\begin{abstract}
А.М. Соловьев ${ }^{1}$ Ю.Н. Перламутров ${ }^{1}$, И.М. Корсунская ${ }^{2}$
${ }^{1}$ ГОУ ВПО «Московский государственный медико-стоматологический университет имени А.И. Евдокимова»

${ }^{2}$ Лаборатория физико-химических и генетических проблем дерматологии Центра теоретических проблем физико-химической фармакологии РАН
\end{abstract}

\title{
State of the immune system of patients with recurrent urogenital infections
}

${ }^{1}$, Yu.N. Perlamutrov' ${ }^{1}$ I.M. Korsunskaya ${ }^{2}$

${ }^{1}$ Moscow State University of Medicine and Dentistry

${ }^{2}$ Federal State Institution of Science Center for Theoretical Problems of Physicochemical Pharmacology Russian Academy of Sciences

\section{Аннотация}

Кроме экономических и социальных условий рост урогенитальных инфекций обусловлен современными особенностями течения этих заболеваний, основными из которых являются стёртая клиническая картина и длительное рецидивирующее течение [1]. Это увеличивает возможность передачи возбудителей урогенитальных инфекций при половых контактах и, таким образом, также способствует росту показателей заболеваемости $[2,3]$.
Среди других проблем следует отметить часто встречающуюся неадекватность этиотропной терапии, которая может способствовать хроническому и осложнённому течению урогенитальных инфекций [4]. Лечение больных с рецидивирующими урогенитальными инфекциями представляет для врача наиболее сложную задачу, так как в этих случаях неоднократное применение иногда даже нескольких терапевтических методов не приводит к элиминации возбудителя и клиническому излечению. 
Для более широкого и универсального изучения методов лечения рецидивирующих инфекций урогенитального тракта мы выбрали заболевания, вызванные различными классами возбудителей - бактиериальной, вирусной и грибковой природы. При этом остановили свое внимание на наиболее распространенных, часто рецидивирующих и социально-значимых инфекциях.

Среди урогенитальных инфекций, вызванных патологическими агентами бактериальной природы, наибольшее распространение имеет хламидийная инфекция, среди вирусных заболеваний - папилломавирусная инфекция, а среди грибковых - урогенитальный кандидоз $[5,6]$.

В мире ежегодно регистрируется около 89 млн. больных урогенитальным хламидиозом [7]. В России уровень заболеваемости урогенитальной хламидийной инфекцией в 2011 составил 66,3 на 100000 населения [5]. Социально значимым является то, что урогенитальный хламидиоз, чаще встречаясь у молодых людей, преимущественно у женщин, служит причиной бесплодия у 17-20\% супружеских пар $[8,9]$

Среди вирусных инфекций, поражающих аногенитальную область, наиболее распространены герпетическая и папилломавирусная инфекция. Частота встречаемости одного из проявлений папилломавирусной инфекции - аногенитальных бородавок (остроконечных кондилом) составляет 19,1\% [10], а инфицированность вирусом папилломы человека (ВПЧ) среди лиц молодого и среднего возраста в некоторых популяциях достигает $34,4-44,9 \%$ [11, 12]. В России уровень заболеваемости аногенитальными бородавками в 2011 составил 29,4 на 100000 населения [5]. К 50-ти годам 80\% женщин инфицированы вирусом папилломы человека [13]. В результате проведённых эпидемиологических и молекулярно-биологических исследований установлено, что инфицирование женщин ВПЧ является важнейшим фактором канцерогенеза шейки матки $[14,15]$.

Среди инфекций влагалища кандидоз стоит на втором месте после бактериального вагиноза [16], а по некоторым данным даже на первом [17]. Частота вагинального кандидоза неуклонно возрастает и составляет по оценкам разных авторов от 26 до 40-45\% в структуре инфекционной патологии нижнего отдела половой системы [18-20]. Вагинальный кандидоз наиболее часто поражает женщин репродуктивного возраста - у 75\% женщин хотя бы один раз в течение репродуктивного периода, а 50\% женщин имеют повторные эпизоды [21]. Заболеваемость возрастает во время беременности, встречаясь не менее чем у 20\% беременных [22]. В последние годы всё чаще встречаются длительно текущие, рецидивирующие формы вагинального кандидоза - примерно 5\% женщин страдает рецидивирующим вульвовагинальным кандидозом (РВВК) [23].

Одной из причин рецидивирующего течения урогенитальной хламидийной инфекции может являться персистенция Chlamydia trachomatis в организме человека. Образование персистирующих форм хламидий сопровождается снижением метаболической активности микроорганизмов, отсутствием их размножения, длительным сохранением в клетках-мишенях атипичных включений, содержащих неразвивающиеся ретикулярные тельца C. trachomatis, резистентные к антибиотикам.

Основным клиническим проявлением папилломавирусной инфекции генитальной области являются остроконечные кондиломы. Важнейшая причина клинической манифестации этой инфекции и ее рецидивирующего течения, как и кандидоза - наличие нарушений в иммунной системе макроорганизма.

Нами было обследовано 258 пациентов, из них 179 больных рецидивирующим урогенитальным хламидиозом (РУГХ), 47 - рецидивирующими остроконечными кондиломами (РОКК) и 32 - рецидивирующим урогенитальным кандидозом (РУГК).

Причиной рецидивирования урогенитальной хламидийной инфекции у всех 179 пациентов являлось наличие персистирующих форм хламидий, подтверждённое культуральным методом.

У 47 больных рецидивирующими остроконечными кондиломаминаблюдалось рецидивирование остроконечных кондилом, несмотря на их удаление различными деструктивными методами. На момент исследования у всех больных имелись остроконечные кондиломы.

В работу включили 32 больных урогенитальным кандидозом - женщины с РВВК и мужчины с кандидозным баланопоститом. Диагноз кандидоза ставился на основании клинической картины и тестирования отделяемого из половых путей микроскопическим методом. Длительность заболевания составляла от 2 месяцев до 12 лет. В исследование включали больных рецидивирующим кандидозом, у которых с момента последнего курса лечения прошло не менее 2 и не более 4 не- 
дель. Предшествующая терапия проводилась у всех больных и включала как местное (нистатин, клотримазол, низорал, пимафуцин, певарил), так и общее лечение (нистатин, низорал, пимафуцин, орунгал, ламизил).

Оценку иммунного статуса пациентов проводили на основе определения субпопуляционного состава лимфоцитов периферической крови, который выявляли при использовании моноклональных антител на проточном цитофлуориметре.

Функциональные реакции нейтрофилов у больных РОКК и РУГК исследовали по интенсивности продукции активных радикалов и по способности к фагоцитозу. Продукцию нейтрофилами активных радикалов определяли по интенсивности хемилюминесценции в образцах цельной крови с удалением эритроцитов лизисом в хлористом аммонии. В каждом образце крови исследовали спонтанную и индуцированную люминолзависимую люминесценцию.

Концентрации IgA, IgG, IgM в крови измеряли методом иммунотурбодиметрии (реагенты фирмы «Human4», Германия).

С целью определения активации макрофагов слизистой цервикального канала у больных РУГК проводили цитохимические исследования с определением неспецифической эстеразы (НЭ). Концентрацию цитокинов (IL-1 $\beta$, IL-8, TNFo, IFN $\gamma$, IL-4 и IL-10) и секреторного иммуноглобулина А определяли твердофазным иммуноферментным методом по методикам Caltag Laboratories, USA.

В качестве группы условно здоровых (“норма”) были выбраны 552 человека из компьютерной базы иммунологических исследований лаборатории активации иммунитета ГНЦ Институт иммунологии ФМБА, содержащей более 5000 исследований. Критерием включения в группу условно здоровых являлось отсутствие инфекционных процессов, онкологических заболеваний, недавних хирургических вмешательств или травм.

При обследовании больных РУГХ признаки недостаточности иммунной системы установили у $140(78,21 \%)$ больных.

Выделив группу из 140 больных, имеющих признаки недостаточности иммунной системы, мы проанализировали разброс иммунологических показателей относительно min-max значений контрольной группы. Выявили статистически достоверное $(\mathrm{p}<0,05)$ уменьшение количе- ства $\mathrm{CD}^{+}$-клеток (менее $0,9 \times 10^{9} /$ л) - у 33 $(23,57 \%)$ больных, $\mathrm{CD}^{+}$-клеток (менее $0,48 \mathrm{x}$ $10^{9} /$ л) - у 75 (53,57\%), CD8 ${ }^{+}$-клеток (менее 0,25 х $10^{9} /$ л) - у $46(32,86 \%), \mathrm{CD}_{2}^{+}$-клеток (менее 0,1 х $10^{9} /$ л) - у $104(74,29 \%), \mathrm{CD} 21^{+}$-клеток (менее 0,1 x 10\%/л) - у $104(74,29 \%)$, CD16 нее 0,17 × $10^{9} /$ л) - у $32(22,86 \%), \mathrm{HLADR}^{+}$-клеток (менее 0,1 х 109/л) - у 45 (32,14\%)больных, уровня IgG (менее 700 мг\%) - у 41 (29,29\%)больных.

При сравнении средних иммунологических показателей 140 больных, имеющих признаки недостаточности иммунной системы, с такими же показателями контрольной группы, выявили достоверное повышение процентного содержания лимфоцитов $(30,5 \pm 0,69 ; \mathrm{p}<0,01)$, уровня IgA $(221,32 \pm 9,44 ; \mathrm{p}<0,001)$, снижение количества лейкоцитов $(6,13 \pm 0,15 ; \mathrm{p}<0,05)$, относительных и абсолютных показателей $\mathrm{CD} 16^{+}$-клеток $(13,21 \pm 0,69$ и $0,22 \pm 0,01 ; \mathrm{p}<0,01), \mathrm{CD} 21^{+}$-клеток $(4,59 \pm 0,22$ и $0,09 \pm 0,01 ; \mathrm{p}<0,01$ и $\mathrm{p}<0,05)$, относительных показателей $\mathrm{CD}^{+} 2^{+}$-клеток $(3,89 \pm 0,21$; $\mathrm{p}<0,05)$ и $\mathrm{HLADR}^{+}$-клеток $(8,98 \pm 0,89 ; \mathrm{p}<0,05)$.

Исследования иммунного статуса проводили у 47 пациентов с РОКК. Иммунный статус больных рецидивирующими остроконечными кондиломами характеризовался снижением процентного содержания CD4+ T-хелперов у 16 (34,04\% больных), показателей пролиферации В-лимфоцитов (в ответ на активацию ЛПС) у 13 (27,66\%), фагоцитарного индекса у 25 (53,19\%) больных, повышением количества CD3+ лимфоцитов у 15 $(31,91 \%)$ больных, NK-клеток у 23 (48,94\%) больных, процента активированных HLADR+ NKклеток у 29 (61,7\%) больных, процента CD3CD16+56- NK-клеток у 25 (53,19\%) больных, процента CD3-CD16+56+ NK-клеток у 18 $(38,3 \%)$ больных, количества цитолитических NK-клеток, содержащих перфорин, у 24 (51,06\%) больных, активированных CD4+25+ клеток у 47 (100\%), CD4+CD45RA+RO+ клеток у $15(31,91 \%)$ больных, CD $8+\mathrm{CD} 45 \mathrm{RA}+\mathrm{RO}+$ клеток у 17 (36,17\%) больных, CD8+25+ Tлимфоцитов у 20 (42,55\%) больных, показателей спонтанной пролиферации у 17 (36,17\%) больных, спонтанной хемилюминесценции - у 20 (42,55\%) больных, хемилюминесценции, индуцированной ФМА, - у 25 (53,19\%) больных, пролиферации Т-лимфоцитов (в ответ на активацию ФГА) у 30 (63,83\%) больных, индекса пролиферации Т-лимфоцитов (в ответ на активацию ФГА) у 17 (36,17\%) больных, показателей пролиферации В-лимфоцитов (в ответ на активацию ЛПС) у 17 (36,17\%), содержания IgG у 24 (51,06\%) больных. 
При сравнении средних иммунологических показателей больных рецидивирующими остроконечными кондиломами с такими же показателями контрольной группы, выявили следующие статистически достоверные изменения: повышение количества лейкоцитов $(6546 \pm 1783,4, \mathrm{p}<0.001)$, лимфоцитов $(2021 \pm 536,8, \mathrm{p}<0.001), \mathrm{CD}^{+}$$(1367 \pm 396,1, \mathrm{p}<0.001)$ и $\mathrm{CD} 8^{+}$-клеток $(522 \pm 186,4$, $\mathrm{p}<0.001)$, IgG $(1179 \pm 324,8, \mathrm{p}<0.01)$, относительных и абсолютных показателей NK-клеток $(21 \pm 6,5$ и $435 \pm 181,9, \mathrm{p}<0.001)$ и NK-клеток, со-

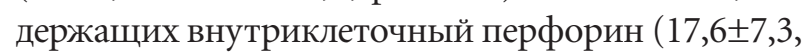
$\mathrm{p}<0.05$ и $368 \pm 196,1, \mathrm{p}<0.001)$, процентного содержания NKHLADR ${ }^{+}$-клеток $(19,4 \pm 10,7, \mathrm{p}<0.001)$, $\mathrm{CD}^{+}{ }^{+} \mathrm{HLADR}^{+}$-клеток $\quad(14,2 \pm 6,1, \quad \mathrm{p}<0.01)$, $\mathrm{CD} 4^{+} \mathrm{CD} 25^{+}$-клеток $(38 \pm 9.3, \mathrm{p}<0.001), \mathrm{CD}^{+}$ $\mathrm{CD} 25^{+}$-клеток $(4,64 \pm 3,6, \mathrm{p}<0.001)$, показателей спонтанной хемолюминисценции $(344 \pm 284,9$, $\mathrm{p}<0.001)$, хемолюминисценции, индуцированной зимозаном $(9914 \pm 4621,3, \mathrm{p}<0.001)$ и ФМА (11639 $\pm 5610,9, \mathrm{p}<0.001)$, снижение процентного содержания NKCD3-16-56 $6^{+}$клеток $(13,5 \pm 7,0$, $\mathrm{p}<0.05), \mathrm{CD}^{+}(68 \pm 7,5, \mathrm{p}<0.001)$ и $\mathrm{CD}^{+}$клеток $(36 \pm 6,4, \mathrm{p}<0.001), \mathrm{CD} 4^{+} \mathrm{CD} 45^{+} \mathrm{RA}^{-} \mathrm{RO}^{+}$клеток $(57 \pm 9,2, \quad \mathrm{p}<0.05), \quad$ иммунорегуляторного $(1,51 \pm 0,5, \mathrm{p}<0.05)$ и фагоцитарного индексов $(9,23 \pm 3,9, \mathrm{p}<0.05)$.

У большинства больных РУГК показатели иммунной системы укладывались в рамки нормы. Нормальное количество лейкоцитов выявлено у 28 (87,5\%), лимфоцитов - у $24(75,0 \%)$, количество $\mathrm{CD}^{+}{ }^{+}$-клеток - у $22(68,75 \%)$; количество $\mathrm{CD} 4^{+}$-клеток - у $20(62,5 \%)$, количество $\mathrm{CD}^{+}$- клеток - у $26(81,25 \%)$, значение иммунорегуляторного индекса - у $22(68,75 \%)$, количество NKHLADR ${ }^{+}$-клеток - у 32 (100\%),количество CD19+-клеток - у $22(68,75 \%)$, количество NK-клеток - у 18 (56,25\%).

Хотя не выявлено значимых отклонений в показателях основных субпопуляций Т-лимфоцитов - CD3+, CD4+, CD19+, обнаружено превышение процента регуляторных CD4+25+ клеток у 56,25\% больных, а также количество NK-клеток - 25\% больных. Обращает внимание дисбаланс некоторых показателей у больных РУГК. Так, процент активированных CD4+ HLADR+ - клеток у 50\% больных был снижен, а у другой половины пациентов - повышен. Это же касается субпопуляций CD8+ -клеток, которые у 25\% пациентов были повышены и у такого же количества больных снижены. В то же время процент активированных CD8+HLADR+ - клеток был только повышен у $25 \%$ пациентов. Возможно, что этот дис- баланс отразился на повышении иммунорегуляторного индекса у 25\% пациентов.

Изучение свойств фагоцитирующих клеток показало активацию хемилюминесценции, индуцированной зимозаном, у 50\% больных, индуцированной ФМА - у $37,5 \%$, фагоцитирующей способности нейтрофилов - у $28,13 \%$ пациентов.

Выявлена активация сывороточных факторов иммунной защиты больных РУГК. У 68,75\% больных отмечалось повышение содержания IgG, у 56,25\% - повышение содержания $\operatorname{IgA}$, у $37,5 \%$ - IgM.

При сравнении иммунологических показателей больных данной группы с показателями контрольной группы обнаружили признаки активации иммунитета. У больных по сравнению с контрольной группой определили статистически достоверное $(\mathrm{p}<0,05)$ повышение процента активированных CD3+ HLADR+ - клеток $(15,7 \pm 17,7)$, иммунорегуляторного индекса $(2,02 \pm 1,0)$, спонтанной $(255 \pm 173)$ и индуцированной хемолюминисценции $(8468 \pm 3891,1)$, содержания всех определяемых типов иммуноглобулинов (IgG $1262 \pm 239,8 ; \operatorname{IgA} 287 \pm 161,9 ; \operatorname{IgM} 190 \pm 77,3)$.

\section{Состояние врожденного иммунитета}

Проведённый анализ состояния иммунной системы у больных РУГХ показал наличие признаков недостаточности иммунитета у 140 (78,21\%) больных.

Показатели CD16+ клеток, свидетельствующие о количестве естественных киллеров как компоненте врожденного иммунитета, у большинства больных укладывались в min-max границы контрольной группы. Однако почти у каждого четвертого пациента $(22,86 \%)$ этот показатель был снижен. При сравнении показателей с параметрами пациентов контрольной группы выявили статистически достоверное снижение относительного и абсолютного содержания $\mathrm{CD}_{16}{ }^{+}$ клеток $(\mathrm{p}<0,01)$. Поскольку из данных литературы известно о важной роли гамма-интерферона при хламидийной инфекции $[25,26]$, очень значимымкритерием является снижение $\mathrm{CD}_{16}{ }^{+}$- клеток иммунной системы, которые наряду с Т-лимфоцитами продуцируют этот важный цитокин. Из опытов invitro известно, что при недостаточном количестве гамма-интерферона потенцируется образование персистентных форм инфекции $[24,25]$. 
Иммунный статус больных рецидивирующими остроконечными кондиломами характеризовался гиперплазией и активацией NK-клеток. В частности, увеличение абсолютного количества NK-клеток выше max границы контрольной группы наблюдалось у 48,94\% больных, содержание активированных HLA-DR ${ }^{+} \mathrm{NK}-$ клеток было повышенным у 61,7\%, цитолитических NK-клеток с перфорином - у 51,06\%, CD16 56-NK-клеток - у 53,19\% больных.

Особого внимания заслуживает активация популяций NK-клеток, играющих важнейшую роль в противовирусной иммунной защите. Клинические данные о рецидивировании инфекции доказывают, что, несмотря на активацию, указанные звенья противовирусной защиты недостаточно эффективны. Это возможно и не позволяет иммунной системе остановить репликацию вируса. Вероятно, у некоторых больных эффективность защиты недостаточна вследствие снижения фагоцитарной активности нейтрофилов (53,19\% больных).

При сравнении средних иммунологических показателей больных рецидивирующими остроконечными кондиломами с такими же показателями контрольной группы, выявили следующие статистически достоверные изменения: повышение количества лейкоцитов ( $<<0.001)$, относительных и абсолютных показателей NK-клеток и NK-клеток, содержащих внутриклеточный перфорин $(\mathrm{p}<0.001)$, процентного содержания $\mathrm{NKHLADR}^{+}$-клеток $(\mathrm{p}<0.001)$, показателей спонтанной хемолюминисценции, хемолюминисценции, индуцированной зимозаном и ФМА $(\mathrm{p}<0.001)$, снижение процентного содержания NKCD3-16 $56^{+}$клеток $(\mathrm{p}<0.05)$ и фагоцитарного индексов $(\mathrm{p}<0.05)$. Данные результаты показывают активационный вектор функционирования факторов врожденного иммунитета при рецидивирующей папилломавирусной инфекции.

Таким образом, исследования показывают решающую роль NK-клеток и, прежде всего, изотипа $\mathrm{CD} 16^{+} 56^{+} \mathrm{NK}$-клеток в контроле ВПЧинфекции.

При исследовании иммунного статуса у большинства больных рецидивирующим урогенитальным кандидозом показатели иммунной системы укладывались в рамки min-max границ контрольной группы. Если рассматривать врожденный иммунитет, то нормальное количество лейкоцитов выявлено у 28 (87,5\%), количество NK-клеток - у 18 (56,25\%). Однако, у 8 (25\%) больных обнаружено повышение уровня NK-клеток.
Изучение свойств фагоцитирующих клеток показало активацию хемолюминисценции, индуцированной зимозаном, у 50\% больных, индуцированной ФМА - у $37,5 \%$, фагоцитирующей способности нейтрофилов - у $28,13 \%$ пациентов.

При сравнении иммунологических показателей больных данной группы с показателями контрольной группы выявлена тенденция к повышению лейкоцитов в периферической крови у больных рецидивирующим урогенитальным кандидозом. Показатели NK-клеток у пациентов соответствовали параметрам контрольной группы. Выявлена статистически достоверная активация фагоцитирующих свойств клеток - спонтанной и индуцированной хемолюминисценции $(\mathrm{p}<0,05)$

Таким образом, установлено, что у больных хламидийной инфекцией имеется статистически достоверная недостаточность NKклеток, у больных остроконечными кондиломами - их гиперпродукция, а в случае кандидоза - отсутствие значимых изменений NKклеток по сравнению с контролем.

\section{Состояние адаптивного иммунитета}

Проведённый анализ состояния иммунной системы показал наличие признаков недостаточности иммунитета у $140(78,21 \%)$ больных РУГХ. Обнаруженные иммунные нарушения оказались вариабельными, но у каждого их этих больных выявили снижение относительно нижней границы контрольной группы хотя бы одного параметра иммунной системы. В целом у четверти из этих больных выявили снижение количества $\mathrm{CD}^{+}{ }^{+}$и $\mathrm{CD} 16^{+}$-клеток, у трети больных - количества $\mathrm{CD}^{+}$- и $\mathrm{HLADR}^{+}$-клеток, а также уровня IgG, у половины больных - $\mathrm{CD}^{+}{ }^{+}$ клеток, у двух третей больных - количества $\mathrm{CD}_{2} 2^{+}$- и $\mathrm{CD} 21^{+}$-клеток, что свидетельствует о недостаточности приобретенного иммунитета - как клеточного, так и гуморального звеньев. Для сравнения, ни у одного из оставшихся 39 больных не обнаружили снижения параметров иммунной системы относительно min-max границ контрольной группы. Эти результаты полностью подтверждаются статистическим анализом при сравнении с показателями этой группы. У 140 больных, имеющих признаки недостаточности иммунной системы, выявили статистически достоверное снижение количества лейкоцитов $(\mathrm{p}<0,05), \mathrm{CD} 21^{+}$-клеток $(\mathrm{p}<0,05)$, относительных показателей $\mathrm{CD} 72^{+}$-клеток и $\mathrm{HLADR}^{+}$-клеток $(\mathrm{p}<0,05)$. 
У больных рецидивирующими остроконечными кондиломами наряду с NK- клетками наблюдается активация звеньев фагоцитов, $\mathrm{CD} 4^{+} \mathrm{T}$-клеток и $\mathrm{CD}^{+} \mathrm{T}$-клеток. Так, повышение интенсивности спонтанной хемилюминесценции нейтрофилов выявлено у 42,55\% больных. Увеличение количества активированных $\mathrm{CD}^{+} 45 \mathrm{RA}^{+} \mathrm{RO}^{+} \mathrm{T}$-хелперов было зарегистрировано у $31,91 \%$, активированных $\mathrm{CD}^{+} 45 \mathrm{RA}^{+} \mathrm{RO}^{+}$T-клеток было зарегистрировано у $36,17 \%$, активированных $\mathrm{CD}^{+} 25^{+}$ Т-клеток - у 42,55\%, пролиферации Т-лимфоцитов - у 63,83\% больных рецидивирующими остроконечными кондиломами.

Активные иммунные реакции NK-клеток, фагоцитов и Т-клеток сопровождались усиленным синтезом антител класса G. Содержание $\operatorname{IgG}$ выше верхней границы нормы наблюдалось у $51,06 \%$ больных.

Примечательны признаки декомпенсации иммунной защиты, которые выражались в истощении содержания $\mathrm{CD} 4^{+} \mathrm{T}-$-клеток у $34,04 \%$, снижении фагоцитарного индекса у $53,19 \%$ и нарастании количества регуляторных $\mathrm{CD} 4^{+} 25^{+}$Т-клеток, способных подавлять функции других Т-клеток, у $100 \%$ больных рецидивирующими остроконечными кондиломами.

При сравнении средних иммунологических показателей больных рецидивирующими остроконечными кондиломами с такими же показателями контрольной группы, выявили следующие статистически достоверные изменения показателей адаптивного иммунитета: повышение количества лимфоцитов $(\mathrm{p}<0.001), \mathrm{CD}^{+}-$и $\mathrm{CD}^{+}$-клеток $(\mathrm{p}<0.001)$, IgG $(\mathrm{p}<0.01), \mathrm{CD}^{+} \mathrm{HLADR}^{+}$-клеток $(\mathrm{p}<0.01)$, $\mathrm{CD} 4^{+} \mathrm{CD} 25^{+}$-клеток $(\mathrm{p}<0.001), \mathrm{CD} 8^{+} \mathrm{CD} 25^{+}$-клеток $(\mathrm{p}<0.001)$, снижение процента $\mathrm{CD}^{+}{ }^{+}$и $\mathrm{CD} 4^{+}$ клеток $(\mathrm{p}<0.001), \mathrm{CD} 4^{+} \mathrm{CD} 45^{+} \mathrm{RA}^{-} \mathrm{RO}^{+}$клеток $(\mathrm{p}<0.05), \quad$ иммунорегуляторного индекса $(\mathrm{p}<0.05)$. Данные результаты характеризуют изменения в иммунной системе у больных рецидивирующей папилломавирусной инфекцией как активационные с признаками декомпенсации.

При исследовании иммунного статуса у большинства больных рецидивирующим урогенитальным кандидозом показатели иммунной системы укладывались в рамки min-max границ контрольной группы.

У ряда пациентов обнаружили как признаки депрессии в иммунной системе, так и признаки активации иммунитета. Обращает внимание снижение у некоторых больных ряда по- казателей за пределы нижних границ контрольной группы. Так, выявили уменьшение количества $\mathrm{CD} 8^{+}$-клеток - у $8(25,0 \%)$ больных; снижение активированных CD4 ${ }^{+} \mathrm{HLADR}+$-клеток - у 16 (50\%). Кроме этого, у незначительного количества пациентов обнаружили снижение В-клеток (у 6 (18,75\%)).

У других пациентов выявлены признаки активации иммунной системы, особенно примечательно повышение у 16 (50\%) больных количества активированных CD4+HLADR ${ }^{+}$-клеток и регуляторных $\mathrm{CD} 4+\mathrm{CD} 25+\mathrm{T}$-хелперов у 18 $(56,25 \%)$ пациентов. Кроме этого выявили повышенное количество CD4 $4^{+}$- клеток - у 8 (25\%); $\mathrm{CD}^{+}$- клеток - у 8 (25\%); активацию сывороточных факторов иммунной защиты у 22 $(68,75 \%)$ больных.

При сравнении иммунологических показателей больных данной группы с показателями контрольной группы обнаружили признаки активации иммунитета. У больных определили статистически достоверное повышение активированных CD3+HLADR+ - лимфоцитов $(\mathrm{p}<0,05)$. При этом показатели CD4+-клеток имели тенденцию к повышению, а количество CD8+-лимфоцитов - к снижению. Данный дисбаланс в субпопуляционном составе Тлимфоцитов особенно демонстративно проявлялся при анализе соотношения CD4+/ $\mathrm{CD} 8+$ (иммунорегуляторный индекс), который у больных рецидивирующим урогенитальным кандидозом был достоверно $(\mathrm{p}<0,01)$ повышенным по сравнению с контрольной группой. Выявленные изменения в некоторой степени опровергают литературные данные, по которым состояние иммунодефицита является характерным для больных рецидивирующим кандидозом [26, 27].

Повышение количества CD3+HLADR+ клеток $(\mathrm{p}<0,05)$ отражает активационную потенцию лимфоцитарного пула, а достоверное повышение иммуноглобулинов всех определямых классов $(\mathrm{p}<0,05)$ - показывает активацию сывороточных факторов иммунной защиты. Следовательно, у больных рецидивирующим урогенитальным кандидозом отмечается тенденция к повышению количества лимфоцитов с преимущественной Th1 потенцией и активация Th2-поляризованных лимфоцитов. Данный факт может свидетельствовать о развитии иммунного ответа преимущественно по Th-2 пути - созреванию клеток антителопродуцентов в ответ на стимуляцию антигенами клеточной стенки гриба. 
Кроме этого, выявленные изменения свидетельствуют об активации иммунной системы. Статистически достоверный рост популяции активированных лимфоцитов, презентирующих HLADR антиген показывает, что идет стимуляция направленная на борьбу с грибковой инфекцией. Кроме того, повышение количества иммуноглобулинов свидетельствует об активации сывороточных факторов защиты.

Исследование показало, что рецидивирование урогенитальных заболеваний может проис- ходить как в условиях недостаточности иммунитета, так и при его активации. Несмотря на выявленное разнообразие иммунологических отклонений, сам факт хронизации инфекции свидетельствует о несостоятельности иммунной защиты, которая оказывается неспособной избавить организм от возбудителя.

Таким образом, при рецидивирующих инфекциях урогенитального тракта активное иммунотропное воздействие может стать частью комбинированной терапии, обеспечивающей достижение удовлетворительных результатов лечения.
1. Липова Е.В., М.Н. Болдырева, Д.Ю. Трофимов, Ю.Г. Витвицкая, И.Ю. Чухриенко, М.А. Мирзоянц. Урогенитальные инфекции, обусловленные условно-патогенной биотой у женщин репродуктивного возраста. Учебное пособие. Москва, 2009, 46 с.

2. Молочков В.А. Гонорея и ассоциированные инфекции: руководство для врачей/ В.А.Молочков, А.Е.Гущин. Москва, 2006, 208c.

3. Инфекции, передаваемые половым путем. Руководство для дерматовенерологов, акушеров-гинекологов, урологов, инфекционистов, педиатров, семейных врачей и руководителей здравоохранения. Институт здоровья семьи, Москва 2009, 168с

4. Потекаев Н.Н., Белоусова Т.А., Горячкина М.В., Савенков В.В. Современные подходы к рациональному выбору этиотропной терапии урогенитальных инфекций у женщин. Consiliummedicum, 2010, №4, с.39-43

5. Кубанова А.А., Бакулев А.Л., Глузмин М.И., Евстигнеева Н.П. и др. Ведение больных инфекциями, передаваемыми половым путем, и урогенитальными инфекциями. Клинические рекомендации РОДВ. Москва 2012 112с

6. Иванова МА, Полев АВ, Поршина ОВ, Гайдарова АЭ, Шаповалов ВС. Заболеваемость инфекциями, передаваемыми половым путем, в Российской федерации в 2011 году. Сборник тезисов II Московского форума «дерматовенерология и косметология: синтез науки и практики» 17 19 октября 2012: 19-20.

7. Smiss I. Epidemiology of Chlamydia trachomatis. Internatiol handbook of Chlamydia ed. T.R. Moss. - UK, 2008. - P. 1-11.

8. Tebb K.P. Screening sexually active adolescents for Chlamydia trachomatis: What about the boys? / Tebb K.P., Pantell R.H., Wibbelsman C.J., Neuhaus J.M. // American Journal of Public Health - 2005. - v.95 - P.1806-1810.

9. Frye J. C. Screening and Treatment Guidelines for Chlamydia trachomatis in Incarcerated Adolescents / Frye J. C., Wallace L., Scott Chavez R., David A.L. // A Review Journal of Correctional Health Care. - 2008 - v.14 - P.89.

10. Ван Крог Д., Лейси С. Д., Гросс Д., Баракко Р., Шнайдер А. Европейское руководство по аногенитальным бородавкам // ИППП. 2002. 3. С. 29-37.

11. Александрова Ю. Н., Лыщев А. А., Сафронникова Н. Р. и др. Папилломавирусная инфекция у здоровых женщин Санкт-Петербурга // Вопр. онкол. 2000; 46 (2): 175-179.
12. Коломиец JI.А. Генитальная папилломавирусная инфекция и рак шейки матки Текст. /Л.А.Коломиец, Л.Н.Уразова. Томск: Изд-во НТЛ, 2002. - 100 с.

13. Прилепская В.Н., Костава М.Н. Возможности терапии папилломавирусной инфекции. РМЖ 2009; 17 (1):16-19.

14. Башмакова М.А., Савичева А.М. Вирусы папилломы человека и их роль в образовании опухолей. Учебное пособие. М.: Медицинская книга; Н. Новгород: НГМД, 1999. $-16 \mathrm{c}$.

15. Потекаев Н.Н., Полеско И.В., Гатич Р.З. Остроконечные кондиломы: тактика лечения. Клиническая дерматология и венерология, 2012,№1, с.94-100

16. Кунгуров Н.В., ГерасимоваН.М., И. Ф. Вишневская. Современные представления о лечении урогенитального кандидоза. Лечащий врач 2004, №6:18-21.

17. Сергеев А.Ю., Сергеев Ю.В. Кандидоз. Природа инфекции, механизмы агрессии и защиты, лабораторная диагностика, клиника и лечение. М: Триада-Х 2001; 472 с.

18. Буданов П.В. Современные подходы к лечению и профилактике генитального кандидоза. Гинекология 2007, том 9, №2:21-30.

19. Bodey G. Candidiasis: Pathogenesis, diagnosis, and treatment. New York: Raven Press 2003; 420.

20. Nyirjesy P., Seeney S., Groby M., Jordan C., Buckley H. Chronic fungal vaginitis: the value of cultures. // Am. J. Obstetr. Gynecol. - 2005. - № 173 (3 Pt. 1). - p. 820-823.

21. Perry C., Whittinton R., McTavish D. Fluconazole. An update of its antimicrobial activity, phannacokinetic properties and therapeutic use invaginal candidiasis. // Drugs.-1995.- Vol. 49. № 6. - P. 994-1006/

22. Сергеев Ю.В., Романовская Т.А., Сергеев А.Ю. Местная терапия кандидозных вульвовагинитов. Русский медицинский журнал 2002, №7, 351-353

23. Хамаганова И.В. Кандидозный вульвовагинит. Лечащий врач 2007, №3:50-53.

24. Beatty W.L., Byrne G.I., Morrison R.P. Morphological and antigenic characterization of interferon gamma mediated persistent Chlamydia trachomatis infection in vitro // Proc. Natl. Acad. Sci. USA. - 1993. - Vol.90. - P.3998-4402.

25. Beatty W.L., Belanger T., Le K.D. et al. Chlamydial persistence: mechanism of induction and parallels to a stress- 
relate response // Proc. Eur. Soc. Chlamyd. Res. - Paris,1994. P.415-418.

26. Letterio J.J., Lehrnbecher T., Pollack G., Walsh T.J., Chonock S.J. Invasive candidiasis stimulates hepatocyte and monocyte production of active transforming growth factor ?/ // Infection and immunity.-2001.-V69,N8.-P.5115-5120.

27. Лебедева Т.Н. Иммунитет при кандидозе (обзор)/Проблемы медицинской микологии.-2004.-Т.6, №4.-С.8-16.

\section{Сведения об авторах:}

А.М. Соловьев - доцент кафедры кожных и венерических болезней, ГОУ ВПО «Московский государственный медико-стоматологический университет имени А.И. Евдокимова»

Ю.Н. Перламутров - профессор, заведующий кафедрой кожных и венерических болезней ГОУ ВПО «Московский государственный медико-стоматологический университет имени А.И. Евдокимова»

И.М. Корсунская - профессор, заведующая лабораторией физико-химических и генетических проблем дерматологии Центра теоретических проблем физикохимической фармакологии РАН

doctorsolovyov@mail.ru

8-926-218-29-81

Поступила 7.10.2013 г. 